\title{
Van Gölü Doğal Sediment ve Modifiye Sediment Üzerine Krom (III) Adsorpsiyonu (İzoterm ve Termodinamik Analiz Çalışması)
}

\author{
Chrome (III) Adsorption On Van Lake Natural Sediment and Modified Sediment \\ (Isotherm and Thermodynamic Analysis Study) \\ İhsan Alacabey ${ }^{1,2 *}$, Ali Rıza Kul ${ }^{2}$, M. Şakir Ece ${ }^{1}$, Hüseyin Alkan ${ }^{3}$ \\ ${ }^{1}$ Mardin Artuklu Üniversitesi, Sağlık Hizmetleri Meslek Yüksekokulu, Mardin \\ ${ }^{2}$ Van Yüzüncü Yıl Üniversitesi, Fen Fakültesi, Kimya Bölümü, Van \\ ${ }^{3}$ Dicle Üniversitesi, Eczacılık Fakültesi, Diyarbakır
}

\begin{tabular}{|c|c|}
\hline MAKALE BİLGİLERİ & ÖZET \\
\hline Makale geçmişi: & $\begin{array}{l}\text { Sediment, nehirlerin, göllerin, koyların, haliçlerin ve okyanusların tabanında yer alan yeryüzü katmanıdır. } \\
\text { Dünyanın en büyük soda gölü olması, eșine rastlanmayacak büyüklükte ve güzellikte dipten yükselen güncel }\end{array}$ \\
\hline Geliș: 02 Mayıs 2020 & karbonat sütunları içermesi ve su seviyesinde yaşanan değişimler, Van Gölü’nü dünyanın en ilginç göllerinden \\
\hline Düzeltme: 18 Mayıs 2020 & biri yapar. Bu çalışmada Van Gölünden alınan doğal sediment ve asitle $\left(\mathrm{HNO}_{3}\right)$ aktive edilmiş sedimentlerin ağır \\
\hline Kabul: 23 Mayis 2020 & $\begin{array}{l}\text { metal }\left(\mathrm{Cr}^{3+}\right) \text { ile ilişkisi batch adsorpsiyon tekniği kullanılarak saptanmaya çalışılmıştır. Farklı } \\
\text { konsantrasyonlardaki krom }\left(\mathrm{Cr}^{3+}\right) \text { iyonlarının ve pH'ın adsoprsiyon prosesi üzerine etkisi arastırılmıstır. }\end{array}$ \\
\hline Anahtar kelimeler: & $\begin{array}{l}\text { Langmuir, Freundlich, Dubinin-Radushkevich (D-R) ve Temkin adsorpsiyon izotermleri hesaplanmıştır. Hem } \\
\text { doğal sediment (DS) hem de asitle modifiye edilmiș sedimentin (MS) Langmuir adsorpsiyon izoterm modeline }\end{array}$ \\
\hline $\begin{array}{l}\text { Adsorpsiyon, krom, sediment, } \\
\text { termodinamik, adsoprsiyon } \\
\text { izotermleri }\end{array}$ & $\begin{array}{l}\text { uyum sağladığı bulunmuştur. Bununla birlikte hem doğal adsorbent hem de asitle modifiye edilmiş adsorbentin } \\
\text { termodinamik parametreleri hesaplanmış, } \Delta \mathrm{G}^{\circ}<0 \text { değerinin adsoprsiyon prosesinin kendiliğinden gerçekleştiğini } \\
\text { göstermiştir. Doğal sedimentin yüzey alanı } 7.512 \mathrm{~m}^{2} / \mathrm{g} \text {, asit ile aktive edilmiş sedimentin yüzey alanı } 79.456 \mathrm{~m}^{2} / \mathrm{g} \\
\text { tespit edilmiş olup aktivasyon işlemi ile çok yüksek bir yüzey alanı elde edilmiştir. Giles adsorpsiyon izoterm } \\
\text { sistemine göre H tipi eğriye uyduğu görülmüştür. }\end{array}$ \\
\hline
\end{tabular}

Doi: $10.24012 /$ dumf. 731216

\begin{tabular}{|c|c|}
\hline ARTICLE INFO & ABSTRACT \\
\hline Article history: & \multirow{6}{*}{$\begin{array}{l}\text { Sediment is the earth layer located at the base of rivers, lakes, bays, estuaries and oceans. The fact that it is the } \\
\text { largest soda lake in the world, it contains up-to-date carbonate columns, rising from the bottom of unprecedented } \\
\text { size and beauty, and changes in the water level make Van Lake one of the fascinating lakes in the world. In this } \\
\text { study, the relationship between natural sediment and acid }\left(\mathrm{HNO}_{3}\right) \text { activated sediments taken from Van Lake with } \\
\text { heavy metal }\left(\mathrm{Cr}^{3+}\right) \text { was tried to be determined by using batch adsorption technique. The effects of chromium }\left(\mathrm{Cr}^{3+}\right) \\
\text { ions and } \mathrm{pH} \text { at different concentrations on the adsorption process were investigated. Langmuir, Freundlich, } \\
\text { Dubinin-Radushkevich (D-R) and Temkin adsorption isotherms were calculated. Both natural sediment (DS) and } \\
\text { acid-modified sediment (MS) were found to conform to the Langmuir adsorption isotherm model. However, both } \\
\text { the natural adsorbent and the acid-modified adsorbent thermodynamic parameters were calculated, showing that } \\
\text { the } \Delta \mathrm{G}^{\circ}<0 \text { value adsorption process occurred automatically. The surface area of the natural sediment is } 7.512 \\
\mathrm{~m}^{2} / \mathrm{g} \text {, and the surface area of the acid-activated sediment is } 79.456 \mathrm{~m}^{2} / \mathrm{g} \text { and a very high surface area has been } \\
\text { obtained by the activation process. According to Giles adsorption isotherm system, it was observed that it fits the } \\
\text { type } \mathrm{H} \text { curve. }\end{array}$} \\
\hline Received: 2 May 2020 & \\
\hline Revised: 18 May 2020 & \\
\hline Accepted: 23 May 2020 & \\
\hline Keywords: & \\
\hline $\begin{array}{l}\text { Adsorption, chromium, sediment, } \\
\text { thermodynamics, adsoption } \\
\text { isotherms }\end{array}$ & \\
\hline
\end{tabular}

* Sorumlu yazar / Correspondence

İhsan ALACABEY

$\triangle$ ihsanalacabey@hotmail.com

Please cite this article in press as İ. Alacabey, A. R. Kul, M. Ş. Ece, H. Alkan, "Van Gölü Doğal Sediment ve Modifiye Sediment Üzerine Krom (III) Adsorpsiyonu (İzoterm ve Termodinamik Analiz Çalışması)", DUJE, vol. 11, no.3, pp. 1225-1232, September 2020. 


\section{Giriş}

Suyun ağır metallerle kirlenmesi, küresel sanayileşmeyle birlikte büyüyen önemli bir çevre ve sağlık sorunudur. Tarım aktiviteleri, yakıt ve enerji endüstrileri, metal endüstrisi, ağır metal kirliliğinin ana kaynaklarıdır. Ayrıca ağır metaller, yer kabuğunda doğal olarak bulunmaktadır. Ağır metal kirliliği, atık yönetiminin olmaması durumunda insan ve çevre için yıkıcı sonuçlar doğurabilir. Krom ağır metalerdendir ve elektrokaplama ve metal işleme endüstrileri tarafindan atık suyuna karışmaktadır. $\mathrm{Cr}^{3+}$ yiyecek, içme suyu ve hava yoluyla küçük bir miktara kadar insan vücuduna girerler [1]. Endüstrinin pek çok dalında hammaddelerin işlenmesinde kullanılan, çoğu toksik ve kanserojen özellikleri olan ağır metallerin atık suları, çevre kirliliğinin önemli unsurlarındandır.

Vücudumuz için diyetle eser miktarda alınması gerekli elementlerden biri $\mathrm{Cr}^{3+}$ iyonlarıdır. Kromun diğer formları için vücudumuzun ihtiyac1 yoktur [2]. Eser element seviyesinin değişmesi, insanlarda sağlık problemleri gösterebilir [3].

Endüstriyel proseslerden suya karıșan $\mathrm{Cr}^{3+}$; tehlikeli su kirleticisidir [4-14]. $\mathrm{Cr}^{3+}$, cilt alerjilerine ve kansere neden olmaktadır $[6,15]$. EPA'nın $\mathrm{Cr}^{3+}$ için izin verilen limiti içme suyunda 0.1 ppm'i geçmemelidir $[6,16]$.

Sağlığa zararlı ağır metal iyonları, bilinen fizikokimyasal yöntemlerle atık sudan uzaklaştırılabilir [17]. Çevre kirliliğine neden olan ve insan sağlığına zarar veren inorganik ve organik atıkların giderilmesi için yaygın olarak kullanılan yöntemler membran filtrasyonu, kimyasal çöktürme, iyon değişimi, koagülasyon ve adsorpsiyonu içermektedir [17-19]. Adsorpsiyon, sulu çözeltilerden ağır metallerin uzaklaştırılmasında kullanılan yöntemlerden biridir. Bu çalışmada Van Gölünden alınan Doğal sediment (DS) ve asitle aktive edilmiş sediment [Modifiye sediment (MS)], ile sentetik sulardan $\mathrm{Cr}^{3+}$ iyonu adsorpsiyonunun izoterm ve termodinamik analiz çalışmaları yapılmıştır.

\section{Materyal Metod}

\section{Doğal Adsorbentin Hazırlanması (NS)}

Doğal adsorbent olarak kullanılan sediment (dip çamuru), Van Gölü'nün 35-40 metre derinlğinde "orange peel bucket" örnekleyicisi (portakal kabuğu kepçesi) ile alınmıştır. Doğal adsorbent oda sicaklığında kendiliğinden kuruması sağlanmıștır.

\section{Modifiye Adsorbentin Hazırlanması (MS)}

Reaktöre konulan 50 g DS üzerine yavaş yavaş $250 \mathrm{ml} 5 \mathrm{~N} \mathrm{HNO}_{3}$ çözeltisi eklenmiş ve kaynama sıcaklığında (yaklaşık $105{ }^{0} \mathrm{C}$ ) sürekli karıştırılarak 3 saat bekletilmiştir. Reaksiyon ürünleri süzülmüş ve $20 \mathrm{kez}$ distile su ile yıkanarak asit artıkları uzaklaştırılmıştır. Son y1kamada örnek, santrifüj edildikten sonra etüvde $60{ }^{0} \mathrm{C}^{\prime}$ de 48 saat süreyle nemin uzaklaştırılması için bekletilmiştir. Örnek bir porselen havanda ezilerek, kurutma sirasinda oluşan topaklanmalar ögütülmüş ve 235 mesh elekten geçirilerek desikatörde saklanmıştır.

\section{Adsoprsiyon Deneyleri (Konsantrasyon, pH, Sicaklık)}

DS ve MS numuneleri önce $105{ }^{\circ} \mathrm{C}$ 'de kurutulmuş 235 meshlik elekten geçirilmiştir. Deneylerden önce tüm plastik ve cam gereçler standart metotlara göre $1+1$ 'lik $\mathrm{HNO}_{3}$ çözeltisi ile yıkanmıștır [20]. Bu numunelerin farklı konsantrasyonlardaki $\mathrm{Cr}^{3+}$ iyonu $298 \mathrm{~K}, 303 \mathrm{~K}$ ve 313 K'deki sicakliklarda, çözeltiden adsorpsiyonu 5 farklı derişim $(10,25,50,75,100$ ppm) ve 5 farklı $\mathrm{pH}(2,4,6,8,10)$ değeri ile çalıșılmıştır ve istenilen pH'1 elde etmek için nitrik asit $\left(\mathrm{HNO}_{3}\right)$ ve $\mathrm{NaOH}$ kullanılmıștır. Her bir deneme de $1 \mathrm{~g}$ adsorbente karşılık derişimleri ve pH'ları ayarlanmış $250 \mathrm{ml} \mathrm{Cr}\left(\mathrm{NO}_{3}\right)_{3}$ çözeltisi erlen içersine alınmıștır. Daha sonra termostatlı su banyosuna yerleștirilmiștir, sicaklık sabit tutulup, mekanik karıștırıcılar yardımıyla, karıștırma hızı sabit tutularak, 120 dakika adsorpsiyon işlemi gerçekleştirilmiştir. Adsorpsiyon süresi bittikten sonra süzme işlemi gerçekleştirilmiş ve sonrasında çözeltide kalan ağır metal miktarı atomik adsorpsiyon spektroskopisi (AAS) ile okutulup veriler alınarak adsorpsiyon izoterm parametreleri ile adsoprsiyon termodinamik parametreleri hesaplanmıştır.

Batch adsorpsiyon tekniği kullanilarak gerçekleştirilen bu çalışmada birim adsorbent $\left(\mathrm{q}_{\mathrm{e}}\right.$ ) başına adsorbe edilen $\mathrm{Cr}^{3+}$ iyonunun miktarı eşitlik 1 ile hesaplanmıştır [21]:

$q_{e}=\frac{\left(C_{i}-C_{e}\right) V}{m}$ 
Yüzde adsorpsiyon hesaplaması eşitlik 2 kullanılarak hesaplanmıştır [22]:

$$
\text { Yüzde Adsorbe }=\frac{C_{\mathrm{i}}-C_{e}}{C_{\mathrm{i}}} \times 100
$$

$\mathrm{C}_{i}$ : çözeltideki $\mathrm{Cr}^{3+}$ iyonu başlangıç konsantrasyonudur $(\mathrm{mg} / \mathrm{L}) ; \mathrm{C}_{\mathrm{e}}$ : çözeltinin denge derişimi $\mathrm{Cr}^{3+}$ iyonu konsantrasyonu $(\mathrm{mg} / \mathrm{L})$; $\mathrm{V}$ : çözeltinin hacmidir (L) ve $\mathrm{m}$ : sedimentin ağırlığıdır (g).

\section{Sonuçlar ve Tartışma}

\section{DS ve MS'in Karakterizasyonu}

DS ve MS'lerinin spesifik yüzey alanın BET karakterizasyonda sirasiyla $7.512 \mathrm{~m}^{2} / \mathrm{g}$ ve 79.456 $\mathrm{m}^{2} / \mathrm{g}$ olarak bulunmuştur. DS ve MS'lerinin yüzey analiz izotermleri incelendiğinde MS'lerinin spesifik yüzey alanındaki bu artış, asit ile modifikasyon işleminde karbonat grupları karbondioksit olarak parçalanıp ortamdan ayrılmasından kaynaklanmaktadır. DS ve MS adsorpsiyon ve desorpsiyon izotermleri Şekil 1 ve Şekil 2' de görülmektedir. IUPAC sinıflandırmasına göre Şekil 1 ve Şekil 2' de gösterildiği gibi hem DS hem de MS, tip IIb olduğu tespit edilmiştir [23].

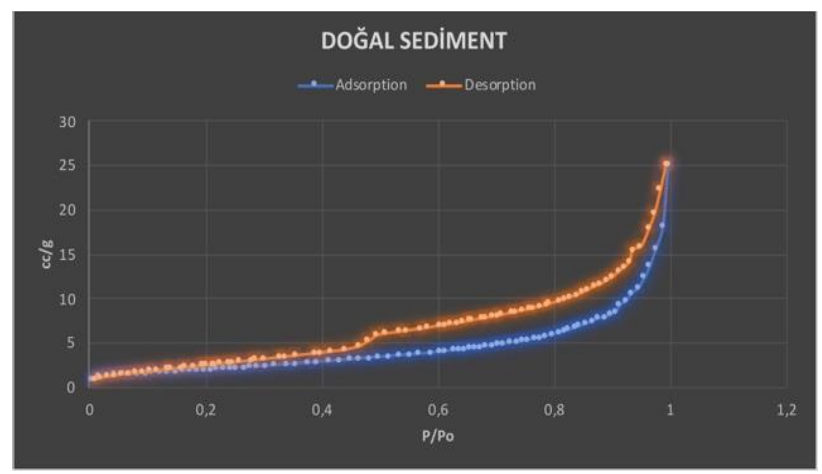

Şekil 1. DS'nin adsorpsiyon ve desorpsiyon izoterm grafiği

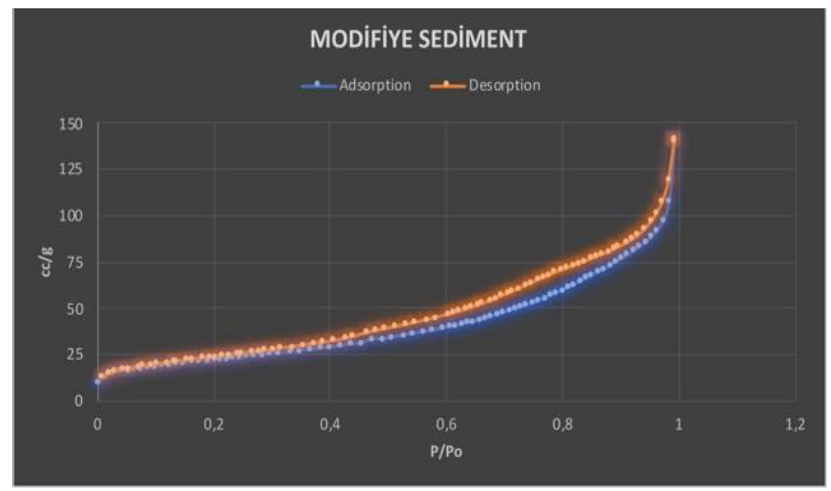

Şekil 2. MS'nin adsorpsiyon ve desorpsiyon izoterm grafiği

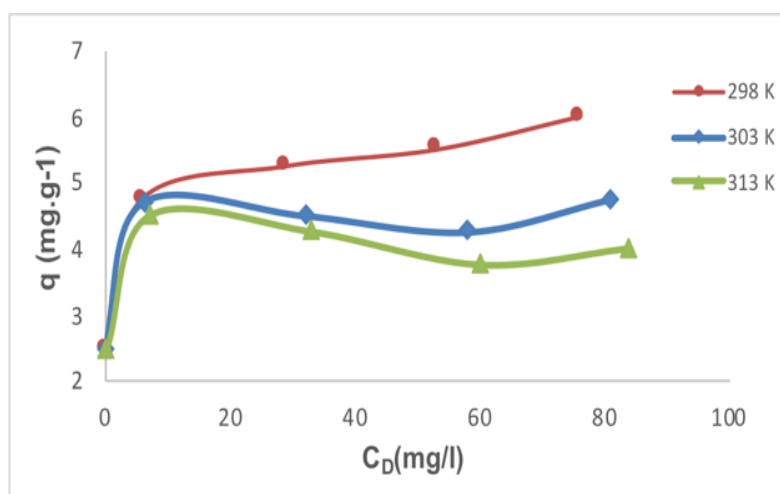

Şekil 3. $\mathrm{Cr}^{3+}$ için Giles izotermi

Giles izotermine göre $\mathrm{C}_{\mathrm{D}}(\mathrm{mg} / \mathrm{L})$ değerlerinin $\mathrm{q}$ $(\mathrm{mg} / \mathrm{g})$ değerlerine karşı çizilen grafik, 4 ana sinifta incelenmektedir. Giles bunları S, L, H ve C tipi eğri olarak sınıflandırmıştır. Bu çalışmada Gilese izotermine göre $H$ tipi eğriye uyduğu tespit edilmiştir. L tipi eğrinin özel bir durumu olan $\mathrm{H}$ tipi eğri; çözünmüş maddenin seyreltik derişimlerinde ya tamamen adsorplanır ya da çözeltide ölçülemeyecek kadar az miktarda kaldığını gösterir [24, 25].

Șekil 4'de verilen DS'nin FTIR spektrumu incelendiğinde $1445.87 \mathrm{~cm}^{-1}$ piki karbonata ait olduğu görülmektedir. Sedimentin ağırlıklı olarak mineral karbonatlardan meydana geldiğ $i$ ifade edilebilir. $3565-3300 \mathrm{~cm}^{-1}$ arasında bulunan pik sedimentin yapısına bağlı olan $\mathrm{H}_{2} \mathrm{O}$ daki O$\mathrm{H}$ esneme bandidır. Silikat yapısında bulunan SiO titreşimine ait pikler ise $950 \mathrm{~cm}^{-1}$ ve 1100 $\mathrm{cm}^{-1}$ deki piklerdir. $875 \mathrm{~cm}^{-1}$ deki pikde sedimentin yapısında bulunan karbonatlardan kaynaklanmaktadır. Şekil 5'de verilen MS'nin FTIR spektrumu incelendiğinde asit işlemine tabi tutulan örneklerde yapıdaki karbonatlar parçalanıp $\mathrm{CO}_{2}$ olarak ortamdan ayrıldığından doğal yapıdaki karbonata ait pikler yok olmuştur.

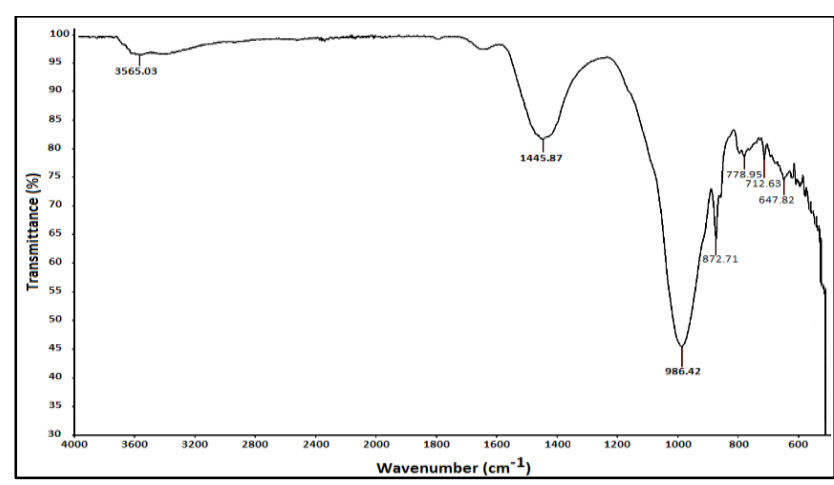

Şekil 4. DS'nin FTIR spektrumu 


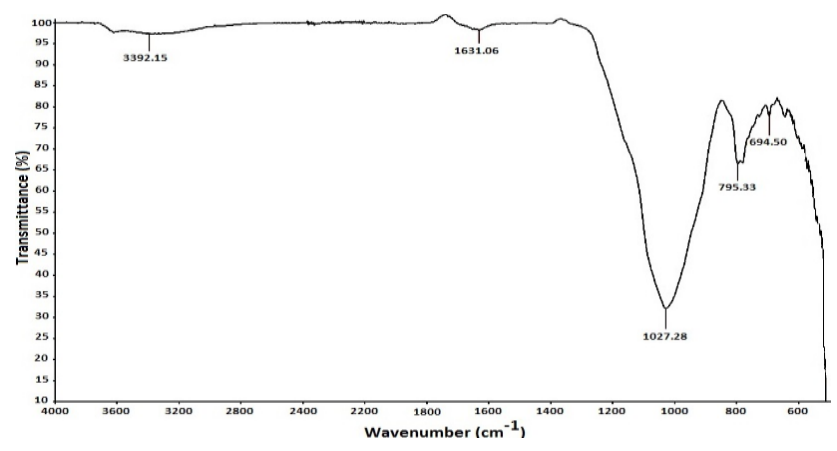

Şekil 5. MS'nin FTIR spektrumu

DS ve MS'nin yapısının SEM Görüntüleri sırasıyla Şekil 6 ve Şekil 7' de verilmiştir. DS yüzeyi modifikasyondan sonra küme formları ile kaplandığı Şekil 7' de görülmektedir. Küme boyutları, bir ile birkaç mikrometre arasında değişir.

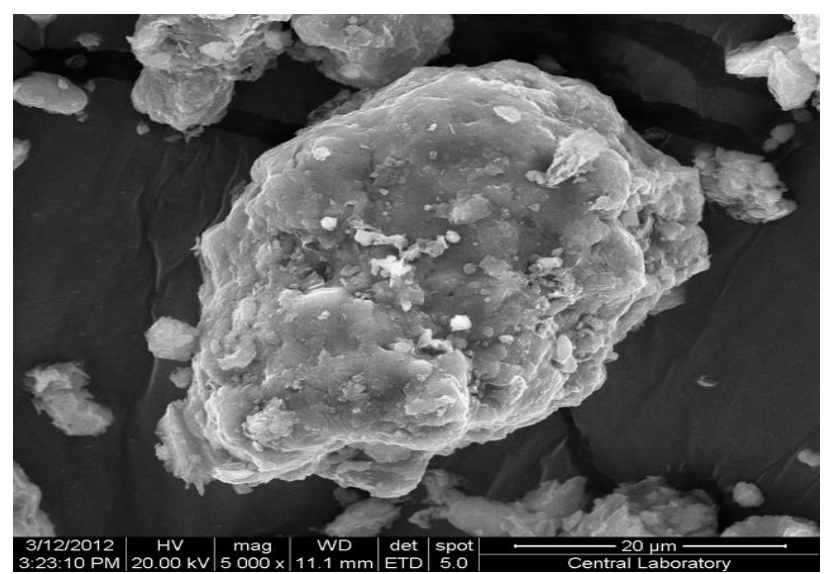

Şekil 6. DS'nin SEM Mikrofotografi

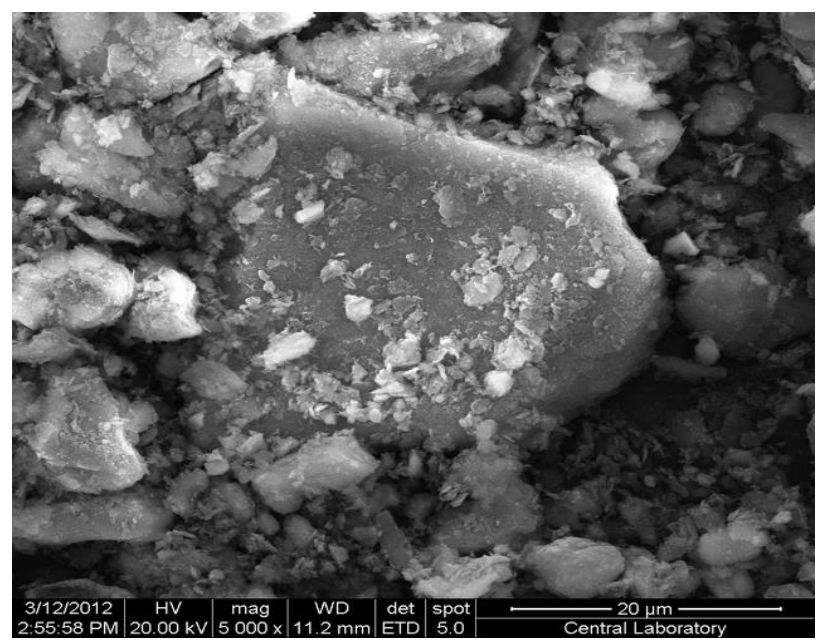

Şekil 7. MS'nin SEM Mikrofotografi

\section{PH değerinin etkisi}

Hem DS'nin hem de MS'nin için Çözeltilerin pH's1 bazik bölgede adsorpsiyonun azaldığ 1 Şekil 8.A'da görülmektedir. Çünkü çözelti pH'1, hem adsorbanın yüzeyindeki bağlanma bölgelerini hem fonksiyonel grupları hem de adsorbat türlerinin yük profillerini etkilemekte ve bunun sonucu olarak da adsorban ve adsorbat türleri arasındaki etkileșimlere neden olmaktadır [26]. Bu azalma kullandığımız adsorbentin bazik karekterli olduğunu göstermektedir.

\section{Konsantrasyonun Etkisi}

DS'in ve MS'in sirasiyla $\mathrm{Cr}^{3+}$ iyonunun 10.0100.0 ppm aralığındaki farklı çözeltilerin adsorpsiyon kapasitesine derişimin etkileri Şekil 8.B'de gösterilmiştir. En yüksek adsorpsiyonu MS'nin sağladığı tespit edilmiştir. Bu farklılık ağır metal adsorpsiyonun MS'nin negatif uçların artmasıyla DS'e göre adsorpsiyon değerinin arttığ 1 , derişimin artmasıyla \% adsorpsiyonun düşmesinden ve düşük derişimde maksimum adsorpsiyon sağlamasından kaynaklanmaktadır. Çünkü derişim arttıkça metal iyonları hem hidratlaşma da hem de kümelenmede artış göstereceğinden serbest iyon olarak veya küçük hidratları halinde bulunamaz.
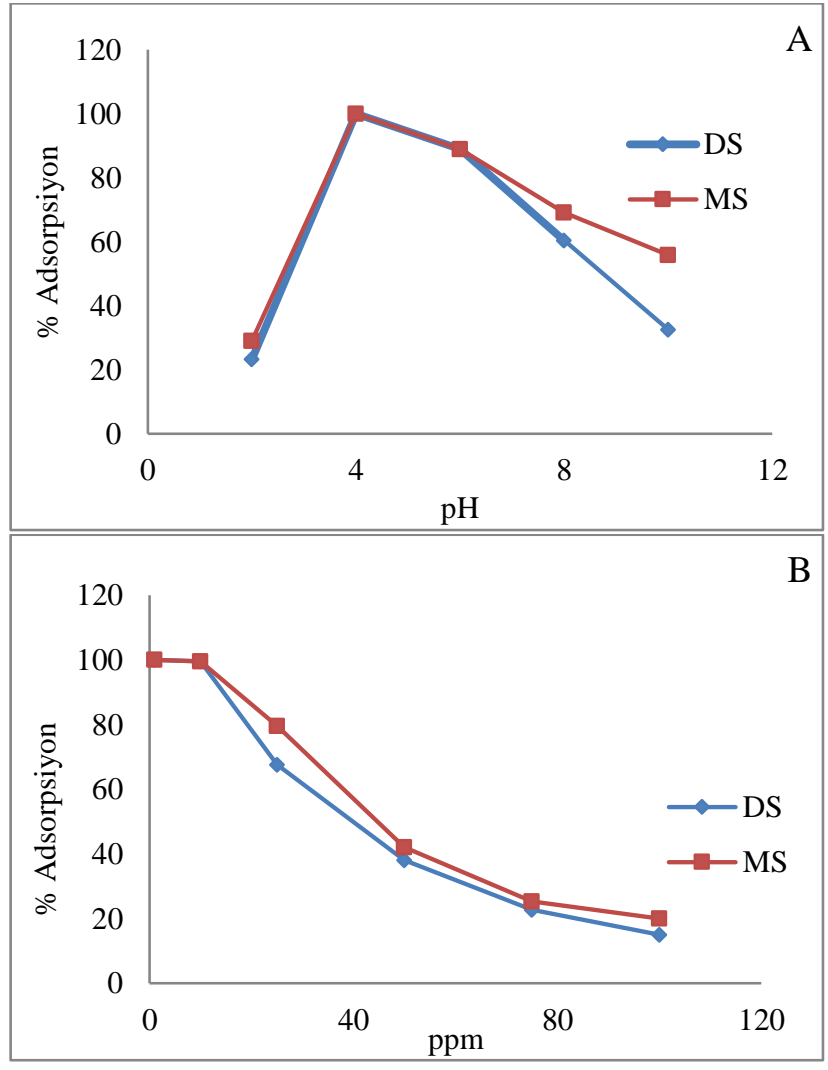

Şekil 8. A) DS ve MS'nin $\mathrm{Cr}^{3+}$ iyonlarının adsorpsiyonuna pH'in etkisi (C: 25 ppm, T:298 $K), B) D S$ ve $M S$ 'nin $\mathrm{Cr}^{3+}$ iyonlarinin adsorpsiyonuna konsantrasyonun etkisi [pH:4, T1: $298 K]$ 


\section{İzoterm Çalışmaları}

Sulu çözeltide kalan $\mathrm{Cr}^{3+}$ iyonların ve adsorbe olan $\mathrm{Cr}^{3+}$ iyonların arasındaki dengeyi tanımlamak için Langmuir, Freundlich, Temkin ve Dubinin-Radushkevich (D-R) izoterm modelleri uyguland.

Langmuir izoterminin lineer denklemi eşitlik 3'te verilmiştir [27].

$\frac{C_{e}}{q_{e}}=\frac{1}{q_{m} b}+\frac{C_{e}}{q_{m}}$

$\mathrm{C}_{\mathrm{e}}(\mathrm{mg} / \mathrm{L})$ denge konsantrasyonudur, $\mathrm{q}_{\mathrm{e}}(\mathrm{mg} / \mathrm{g})$ dengedeki adsorpsiyon miktarıdır, $\mathrm{q}_{\mathrm{m}}(\mathrm{mg} / \mathrm{g})$ maksimum adsorpsiyon kapasitesidir, b (L/mg) adsorpsiyon denge sabitidir [28].

Freundlich izoterminin lineer denklemi eşitlik 4'te verilmiştir [29].

$\ln q_{e}=\ln K_{F}+\frac{1}{n} \ln C_{e}$

$\mathrm{K}_{\mathrm{F}}$ kabaca adsorpsiyon kapasitesinin bir göstergesidir ve $\mathrm{n}$ adsorpsiyon şiddetidir.

Temkin izoterminin lineer denklemi eşitlik 5 'te verilmiştir [30].

$\mathrm{q}_{\mathrm{e}}=\mathrm{B} \ln \mathrm{K}_{\mathrm{T}}+\mathrm{B} \ln \mathrm{C}_{\mathrm{e}}, \mathrm{B}=(\mathrm{RT}) / \mathrm{b}$

$\mathrm{K}_{\mathrm{T}}(\mathrm{L} / \mathrm{mg})$ Temkin izoterm sabitini ve b $(\mathrm{kJ} / \mathrm{mol})$ adsorpsiyon 1sisı ile ilgili bilgi veren Temkin sabitidir.

Dubinin-Radushkevich (D-R) izotermi eşitlik 6,7,8 kullanılarak hesaplanmıştır [22].

$\ln \mathrm{q}_{\mathrm{e}}=\ln \mathrm{q}_{\mathrm{m}}-\mathrm{k} \varepsilon^{2}$

burada, $\mathrm{q}_{\mathrm{e}}$ birim sediment başına çıkarılmış ağır metal miktarıdır (mg/g), $\mathrm{q}_{\mathrm{m}} \mathrm{D}-\mathrm{R}$ adsorpsiyon kapasitesidir (mg/g), k adsorpsiyon enerjisi ile ilgili sabittir $\left(\mathrm{mol}^{2} / \mathrm{kJ}^{2}\right), \varepsilon$ Polanyi potansiyelidir $(\mathrm{kJ} / \mathrm{mol}), \mathrm{R}$ gaz sabitidir $\left(\mathrm{kJ} / \mathrm{K}^{2} \mathrm{~mol}^{2}\right)$ ve sicaklık (K) T'dir.

$\varepsilon=R T \ln \left(1+\frac{1}{C_{e}}\right)$

$\mathrm{E}=(2 \mathrm{k})^{-1 / 2}$

Eşitlik 8'de verilen Adsorpsiyon enerjisi E (kJ/mol), adsorpsiyonun kimyasal, iyon değişimi veya fiziksel adsorpsiyon gibi adsorpsiyon mekanizması hakkında hakkında bilgi verir [31]. $\mathrm{E}$ değerinin büyüklüğü 8 ile $16 \mathrm{~kJ} / \mathrm{mol}$ arasında yer alması, sorpsiyon işlemi iyon değişimi mekanızması üzerinden gerçekleştiğini göstermektedir, $\mathrm{E}>16 \mathrm{~kJ} / \mathrm{mol}$ değerleri için ise sorpsiyon mekanizması kimyasal etkileşim ile açıklanabilir [22].

\section{Termodinamik Çalışmalar}

Adsorpsiyon tipinin belirlenmesi için adsorpsiyon entalpisi $\left(\Delta \mathrm{H}^{\circ}\right)$, adsorpsiyon entropisi $\left(\Delta \mathrm{S}^{\mathrm{o}}\right)$ ve Gibbs serbest entalpisi $\left(\Delta \mathrm{G}^{\mathrm{o}}\right)$ termodimanik açıdan önemli bir yer tutamaktadır $\mathrm{Bu}$ nicelikler sırayla eşitlik (9), (10), (11), (12)'den yaralanılarak hesaplanmıştır [22].

$\Delta \mathrm{G}^{\mathrm{o}}=\Delta \mathrm{H}^{\mathrm{o}}-\mathrm{T} \Delta \mathrm{S}^{\mathrm{o}}$

Burada $\Delta \mathrm{G}^{\circ}$ Serbest enerji değişimi, Gibbs serbest enerjidir $(\mathrm{kJ} / \mathrm{mol}), \Delta \mathrm{H}^{\circ} \quad$ Entalpi değişimidir $(\mathrm{kJ} / \mathrm{mol}), \Delta \mathrm{S}^{\mathrm{o}}$ Entropi değişimidir (kJ/molK), T sicaklıktır (Kelvin).

Adsorpsiyon prosesinde Gibbs serbest enerjisini hesaplanması için $K_{c}$, eşitlik 10 yardımı ile hesaplanmıştır.

$\mathrm{K}_{\mathrm{c}}=\mathrm{C}_{\mathrm{a}} / \mathrm{C}_{\mathrm{e}}$

$\mathrm{K}_{\mathrm{c}}$ Denge sabitidir, $\mathrm{C}_{\mathrm{a}}$ sediment tarafindan tutulan madde konsantrasyonudur $(\mathrm{mg} / \mathrm{L}), \mathrm{C}_{\mathrm{e}}$ Çözeltide kalan madde konsantrasyonudur (mg/L).

$\mathrm{K}_{\mathrm{c}}$ 'nin, başlangıç madde konsantrasyonlarına $\left(\mathrm{C}_{0}\right)$ karşı çizilen grafiğin kesim noktasından bulunan $\mathrm{K}_{\mathrm{c}}{ }^{\mathrm{o}}$ değeri, Eşitlik 11 'de $\mathrm{K}_{\mathrm{c}}{ }^{\mathrm{o}}$ değeri yerine yazilırsa adsorpsiyonun Gibbs serbest enerjisi bulunur. Adsorpsiyon işleminin kendiliğindenlik derecesi Gibbs serbest enerjisi tarafından belirlenir [32].

$\Delta \mathrm{G}^{\mathrm{o}}=-\mathrm{R} \mathrm{T} \ln \mathrm{K}_{\mathrm{c}}^{\mathrm{o}}$

$\ln \mathrm{K}_{\mathrm{c}}^{\mathrm{o}}=\frac{\Delta \mathrm{S}^{\mathrm{o}}-\Delta \mathrm{H}^{\mathrm{o}}}{\mathrm{R}} \times \frac{1}{\mathrm{~T}}$

R Gaz sabitidir (8.314 J mol $\left.{ }^{-1} \mathrm{~K}^{-1}\right)$.

Eşitlik 12 kullanılarak, $\operatorname{lnKc^{0}}$ değerinin 1/T değerine karşı çizilen grafiğin eğiminden $\Delta \mathrm{H}^{\mathrm{o}}$ ve kesim noktasindan da $\Delta \mathrm{S}^{\mathrm{o}}$ hesaplanmaktadır.

Hem DS'leri hem de MS'leri üzerindeki uygun pH'daki $(\mathrm{pH}=4) \mathrm{Cr}^{3+}$ 'ün farklı sıcaklıklardaki $(298 \mathrm{~K}, 303 \mathrm{~K}$ ve $313 \mathrm{~K})$ adsorpsiyonu için Langmuir, Freundlich, Temkin ve DubininRadushkevich (D-R) izoterm parametreleri uygulanmıştır. Langmuir izoterm sabitleri $\mathrm{pH}: 4$, $\mathrm{T}_{3}=313 \mathrm{Cr}^{3+}$ iyonlarının $\mathrm{DS}$ üzerindeki adsorpsiyonunun korelasyon faktörü $\mathrm{R}^{2}=0.9948$ olarak hesaplanmıștır. Aynı șartlarda Freundlich izoterm sabitlerinin hesaplanması için çizilen eğrilerde $\mathrm{Cr}^{3+}$ iyonunun DS üzerindeki 
adsorpsiyonunun korelasyon faktörü $\mathrm{R}^{2}=0.6254$ olarak hesaplanmıștır (Tablo 1). Dubinin-
Radushkevich (D-R) adsorpsiyon izoterminden elde edilen sonuçlara göre; MS monomolekül

Tablo 1. Langmuir, Freundlich, Temkin ve Dubinin-Radushkevich (D-R) izoterm parametreleri A; $D S-\mathrm{Cr}^{3+}$ pH:4. B; MS- $\mathrm{Cr}^{3+} p H: 4$

\begin{tabular}{|c|c|c|c|c|c|c|c|c|c|c|c|c|c|c|}
\hline & \multirow[b]{2}{*}{$\mathrm{T}(\mathrm{K})$} & \multicolumn{3}{|c|}{ Langmuir } & \multicolumn{3}{|c|}{ Freundlich } & \multicolumn{3}{|c|}{ Temkin } & \multicolumn{4}{|c|}{ Dubinin-Radushkevich (D-R) } \\
\hline & & \begin{tabular}{|c|}
$\mathrm{b}$ \\
$(\mathrm{L} / \mathrm{mg})$
\end{tabular} & $\begin{array}{c}\mathrm{q}_{\mathrm{m}} \\
(\mathrm{mg} / \mathrm{g}) \\
\end{array}$ & $\mathrm{R}^{2}$ & $\mathrm{n}$ & \begin{tabular}{|c|}
$\mathrm{K}_{\mathrm{F}}$ \\
$(\mathrm{mg} / \mathrm{g})$
\end{tabular} & $\mathrm{R}^{2}$ & $\begin{array}{c}\mathrm{b} \\
(\mathrm{kJ} / \mathrm{mol})\end{array}$ & \begin{tabular}{|c|}
$\begin{array}{c}\mathrm{K}_{\mathrm{T}} \\
(\mathrm{L} / \mathrm{mg})\end{array}$ \\
\end{tabular} & $\mathrm{R}^{2}$ & \begin{tabular}{|c|}
$\mathrm{q}_{\mathrm{m}}$ \\
$(\mathrm{mol} / \mathrm{g})$ \\
\end{tabular} & $\begin{array}{c}\mathrm{k}_{\mathrm{D}-\mathrm{R}} \\
\left(\mathrm{mol}^{2} / \mathrm{kJ}^{2}\right)\end{array}$ & $\begin{array}{c}\mathrm{E} \\
(\mathrm{kJ} / \mathrm{mol})\end{array}$ & $\mathrm{R}^{2}$ \\
\hline \multirow{3}{*}{$\mathrm{A}$} & 298 & 0.4443 & 3.8168 & 0.9901 & 14.056 & 3.2486 & 0.7455 & 1.6970 & 0.0019 & 0.6830 & 0.0825 & 2.4944 & 16.7 & 0.8774 \\
\hline & 303 & 0.4812 & 3.6127 & 0.9856 & 15.6595 & 3.1376 & 0.6685 & 1.6617 & 0.0028 & 0.6090 & 0.0778 & 2.5534 & 17.1 & 8390 \\
\hline & 313 & 0.4787 & 3.5162 & 0.9948 & 18.180 & 3.1791 & 0.6254 & 1.6224 & 0.0026 & 0.5510 & 0.0764 & & 19.6 & 0.8140 \\
\hline \multirow{3}{*}{ B } & 298 & 0.5527 & 5.9453 & 0.9952 & 8.5562 & 1.7440 & 0.9862 & 2.2670 & 0.0005 & 0.9892 & \begin{tabular}{|l|}
0.1062 \\
\end{tabular} & & 13.6 & 0.9739 \\
\hline & 303 & 1.5522 & 4.6083 & 0.9940 & 11.6144 & 1.6856 & 0.8301 & 1.8297 & 0.0013 & 0.8059 & \begin{tabular}{|l|}
0.0893 \\
\end{tabular} & 2.4158 & 15.1 & 0.9507 \\
\hline & 313 & 1.6431 & 3.9063 & 0.9968 & 14.4718 & 1.6504 & 0.6691 & 1.8863 & 0.0027 & 0.6007 & 0.0804 & 2.5209 & 16.0 & 0.8639 \\
\hline
\end{tabular}

adsorpsiyon kapasitesini arttırdığ 1 Tablo 1'den anlaşılmaktadır.

Tablo 1'de $\mathrm{Cr}^{3+}$ ve iyonlarının DS'i üzerine adsorpsiyonunda $\mathrm{E}$ değerinin $16 \mathrm{~kJ} / \mathrm{mol}$ 'den daha büyük olmasından tutulmanın kimyasal olduğu saptanmıștır. Buna karşın MS'nin $\mathrm{Cr}^{3+}$ ve iyonlarının $\mathrm{E}$ değerinin 8-16 kJ/mol değerleri arasında yer almasından adsorpsiyonun ağırlıklı olarak iyon değişimi olduğu saptanmıştır.

Tablo 2. Adsorpsiyonu için hesaplanan termodinamik parametreler $A ; D S-\mathrm{Cr}^{3+} \mathrm{pH}: 4 . \mathrm{B}$; $M S-\mathrm{Cr}^{3+} \mathrm{pH}: 4$

\begin{tabular}{|c|c|c|c|c|c|}
\hline & $\begin{array}{c}\text { Sıcaklık } \\
\text { (K) }\end{array}$ & $\begin{array}{l}\mathrm{Kc}^{\circ}, \\
\text { Sabit }\end{array}$ & $\begin{array}{c}\Delta \mathrm{G}^{\circ}, \\
\mathrm{kJ} / \mathrm{mol}\end{array}$ & $\begin{array}{c}\Delta \mathrm{H}^{\circ}, \\
\mathrm{kJ} / \mathrm{mol}\end{array}$ & $\begin{array}{c}\Delta \mathrm{S}^{\circ}, \\
\mathrm{kJ} / \mathrm{mol}\end{array}$ \\
\hline \multirow{5}{*}{ A } & 298 & 122.39 & -11.9102 & \multirow{5}{*}{-15.7850} & \multirow{5}{*}{0.0915} \\
\hline & 303 & 87.554 & -11.2662 & & \\
\hline & 318 & 152.9 & -13.0889 & & \\
\hline & 303 & 204.19 & -13.3994 & & \\
\hline & 318 & 204.35 & -13.8437 & & \\
\hline \multirow{5}{*}{ B } & 298 & 122.87 & -11.9199 & \multirow{5}{*}{28.9144} & \multirow{5}{*}{-0.0575} \\
\hline & 303 & 87.957 & -11.2778 & & \\
\hline & 318 & 68.388 & -10.9952 & & \\
\hline & 303 & 309.01 & -14.4432 & & \\
\hline & 318 & 206.78 & -13.8745 & & \\
\hline
\end{tabular}

\section{Sonuçlar}

Adsorpsiyon veriminin, çözelti pH'1, ağır metal iyonlarının konsantrasyonu ve sicaklıkla değiştiği gözlenmiştir. Adsorpsiyonun yaklaşık 120 dakikada dengeye ulaştı̆̆ 1 tespit edilmiştir. Çözeltinin pH'1 bazik olduğunda adsorpsiyonun azalması kullandığımız adsorbentin bazik karakterli olmasından kaynaklanmıștır. $\mathrm{Cr}^{3+}$ iyonlarinın adsorpsiyonunun $\mathrm{pH}=4.0$ ' de maksimum olduğu gözlenmiştir. Adsorpsiyon verimliliklerine bakıldığında $\mathrm{Cr}^{3+}$ iyonlarının MS üzerine adsorpsiyonu DS'den daha fazla adsorbe ettiği gözlenmiştir.

MS'nin içindeki kil minerallerinin kristal yapısından uzaklaşan $\mathrm{Al}^{3+}, \mathrm{Fe}^{3+}, \mathrm{Mg}^{2+}$ gibi iyonların boşalan yerlerinde ortaya çıkan mikro ve mezo-gözeneklerden dolayı özgül gözenek hacmi ve bu gözeneklerin duvarlarından dolayı ise özgül yüzel alanı yükselmiştir [33]. DS'nin yüzey alanı $7.512 \mathrm{~m}^{2} / \mathrm{g}$ olarak belirlenmiştir. MS'nin BET yüzey alanları belirlendiğinde; Kimyasal olarak $\mathrm{HNO}_{3}$ seçildiğinde ise MS yeterince yüksek yüzey alanı $\left(79.456 \mathrm{~m}^{2} / \mathrm{g}\right)$ elde edilmiştir.

DS'lerinin ve MS' lerinin $\mathrm{Cr}^{3+}$ iyonlarının adsorpsiyon verilerinin Langmuir izoterm denklemine daha iyi uyum sağladiğ bulunmuştur, bu sonuç adsorpsiyonun tek tabakalı ve homojen olduğunu göstermektedir.

DS ile $\mathrm{Cr}^{3+}$ iyonlarının uzaklaştırılmasında hesaplanan termodinamik parametrelerden $\Delta \mathrm{H}^{0}$ negatif bulunması prosesin ekzotermik olduğunu göstermektedir [34]. $\Delta S^{0}$ değerinin pozitif bulunması adsoprsiyon sirasinda $\mathrm{Cr}^{3+}$ iyonları çözeltisi ile DS arayüzeyinde düzensizliğinin arttığını göstermektedir. Ayrıca MS için pozitif değerli $\Delta \mathrm{H}^{0}$ prosesin endotermik olduğunu göstermektedir. $\Delta S^{0}$ değerinin negatif bulunması adsorpsiyon sırasında $\mathrm{Cr}^{3+}$ iyonlarının çözeltisi ve MS kat1 - çözelti arayüzeyinde düzensizliğinin azaldığını göstermektedir [35]. 
Hem DS hem de MS için Gibbs serbest enalpisi $\Delta \mathrm{G}^{0}$ değerlerinin negatif bulunması adsorpsiyonun kendiliğinden gerçekleştiğini ifade eder (Tablo2). Asit ile aktivasyon prosesinde, aktivasyonun gerçekleşmesi sebebiyle doğal malzemeye göre yüksek yüzey alanı ve gözenekliliğe sahip katı ürün elde edilmiştir.

\section{Teşekkür}

Bu çalışma Yüzüncü Y1l Üniversitesi Bilimsel Araştırma Projeleri Birimi tarafından 2010 FBE - D126 nolu proje ile desteklenmiştir, finansal yönden destekleyen Yüzüncü Y1l Üniversitesi Bilimsel Araştırma Projeleri Birimi'ne teşekkürlerimi sunarım.

\section{Kaynaklar}

1. Atasoy, N., et al., Levels of heavy metals and certain macro elements in potable and tap water at Van city center. Hacettepe J. Biol. \& Chem, 2011. 39: p. 391-396.

2. Alacabey, ì., Bazı ağır metallerin (kobalt, krom, kadmiyum) doğal ve aktive edilmiş Çaldıran Diatomiti (Çaldıran/Van) üzerindeki adsorpsiyon denge çalışmaları. 2006, Yüksek Lisans Tezi.

3. Alacabey, i.., et al., Determination of Cobalt (Co) level in hair and serum of Gas Station Workers in Van Province. J Environ Sci Toxicol Food Technol, 2017. 11(2): p. 30-32.

4. Chwastowska, J., et al., Speciation of chromium in mineral waters and salinas by solid-phase extraction and graphite furnace atomic absorption spectrometry. Talanta, 2005. 66(5): p. 1345-1349.

5. Karthikeyan, T., S. Rajgopal, and L.R. Miranda, Chromium (VI) adsorption from aqueous solution by Hevea Brasilinesis sawdust activated carbon. Journal of hazardous materials, 2005. 124(1-3): p. 192199.

6. Wei, X., et al., Adsorption behaviors of atrazine and $\mathrm{Cr}$ (III) onto different activated carbons in single and co-solute systems. Powder Technology, 2018. 329: p. 207-216.

7. Godinho, D., et al., Adding value to gasification and co-pyrolysis chars as removal agents of $\mathrm{Cr} 3+$. Journal of hazardous materials, 2017. 321: p. 173-182.
8. Di Natale, F., et al., Removal of chromium ions form aqueous solutions by adsorption on activated carbon and char. Journal of Hazardous Materials, 2007. 145(3): p. 381390.

9. Derya, H., Tekirdağ ilinde bulunan bazı ahırlardan toplanan olgunlaşmış ve olgunlaşmamış gübrelerin besin elementi içeriklerinin belirlenmesi ve tarımsal açıdan değerlendirilmesi. 2013, Namık Kemal Üniversitesi.

10. Anderson, R.A., Chromium and insulin resistance. Nutrition research reviews, 2003. 16(2): p. 267-275.

11. Adriá-Cerezo, D., M. Llobat-Estellés, and A. Mauri-Aucejo, Preconcentration and speciation of chromium in waters using solidphase extraction and atomic absorption spectrometry. Talanta, 2000. 51(3): p. 531536.

12. Agarwal, G., H.K. Bhuptawat, and S. Chaudhari, Biosorption of aqueous chromium (VI) by Tamarindus indica seeds. Bioresource technology, 2006. 97(7): p. 949956.

13. Dubey, S.P. and K. Gopal, Adsorption of chromium (VI) on low cost adsorbents derived from agricultural waste material: a comparative study. Journal of hazardous materials, 2007. 145(3): p. 465-470.

14. Hsu, L., et al., The removal and recovery of $\mathrm{Cr}$ (VI) by Li/Al layered double hydroxide (LDH). Journal of Hazardous Materials, 2007. 142(12): p. 242-249.

15. Kotaś, J. and Z. Stasicka, Chromium occurrence in the environment and methods of its speciation. Environmental pollution, 2000. 107(3): p. 263-283.

16. Lingamdinne, L.P., et al., Biogenic reductive preparation of magnetic inverse spinel iron oxide nanoparticles for the adsorption removal of heavy metals. Chemical Engineering Journal, 2017. 307: p. 74-84.

17. Lin, S.-H. and R.-S. Juang, Heavy metal removal from water by sorption using surfactant-modified montmorillonite. Journal of Hazardous Materials, 2002. 92(3): p. 315-326.

18. Bhattacharyya, K.G. and S.S. Gupta, Kaolinite and montmorillonite as adsorbents for $\mathrm{Fe}$ (III), Co (II) and Ni (II) in aqueous medium. Applied Clay Science, 2008. 41(1-2): p. 1-9. 
19. Tural, S., M.Ş. Ece, and B. Tural, Synthesis of novel magnetic nano-sorbent functionalized with $N$-methyl-D-glucamine by click chemistry and removal of boron with magnetic separation method. Ecotoxicology and environmental safety, 2018. 162: p. 245252.

20. APHA, A., WEF Standard methods for the examination of water and wastewater Washington, DC, USA: American Public Health Association, 1995. 19th ed.

21. Erol, K., The adsorption of calmoduline via nicotinamide immobilized poly (HEMA-GMA) cryogels. Journal of the Turkish Chemical Society Section A: Chemistry, 2017. 4(1): p. 133-148.

22. Alacabey, i., Doğal ve Aktive Edilmiş Van Gölü Sediment (Dip Çukuru) Örneklerinin Bazı Ağır Metallerle Adsorspsiyonun Izoterm ve Termodinamik Analizi, Doktora Tezi, Yüzüncü Yıl Üniversitesi. Fen Bilimleri Enstitüsü, Van, 2014.

23. Sawant, S.Y., R.S. Somani, and H.C. Bajaj, A solvothermal-reduction method for the production of horn shaped multi-wall carbon nanotubes. Carbon, 2010. 48(3): p. 668-672.

24. Giles, C., et al., 786. Studies in adsorption. Part XI. A system of classification of solution adsorption isotherms, and its use in diagnosis of adsorption mechanisms and in measurement of specific surface areas of solids. Journal of the Chemical Society (Resumed), 1960: p. 3973-3993.

25. MAHAMANLIOĞLU, M., İ. KIZILÇIKLI, and A. ÇINARLI, BAZIK BOYAR MADDELERIN AĞAÇLI KÖMÜRLERINDEN ELDE EDILEN AKTIF KARBON ÜZERINDE ADSORPSIYONU. Selçuk Üniversitesi Mühendislik, Bilim ve Teknoloji Dergisi, 2006. 21(3): p. 21-32.

26. Krishnan, K.A., A. Sheela, and T. Anirudhan, Kinetic and equilibrium modeling of liquidphase adsorption of lead and lead chelates on activated carbons. Journal of Chemical Technology \& Biotechnology: International Research in Process, Environmental \& Clean Technology, 2003. 78(6): p. 642-653.
27. Erol, K., DNA adsorption via Co (II) immobilized cryogels. Journal of Macromolecular Science, Part A, 2016. 53(10): p. 629-635.

28. Zhao, X., et al., A green method to synthesize flowerlike $\mathrm{Fe}(\mathrm{OH}) 3$ microspheres for enhanced adsorption performance toward organic and heavy metal pollutants. Journal of Environmental Sciences, 2018.

29. Erol, K., et al., Magnetic diatomite for pesticide removal from aqueous solution via hydrophobic interactions. Environmental Science and Pollution Research, 2019. 26(32): p. 33631-33641.

30. Riza, K.A., et al., Equilibrium, kinetic and thermodynamic studies of nickel adsorption onto natural and modified kaolinites. Fresenius Environmental Bulletin, 2011. 20(5): p. 1155-1166.

31. Caliskan, N., et al., Adsorption of Zinc (II) on diatomite and manganese-oxide-modified diatomite: A kinetic and equilibrium study. Journal of hazardous materials, 2011. 193: $p$. 27-36.

32. Depci, T., et al., Characteristic properties of adsorbed catalase onto activated carbon based adiyaman lignite. Fresenius Environmental Bulletin, 2011. 20(9a): p. 2373-2380.

33. Yalçın, E., Bentonitik killer üzerinde etilen glikol monoetil eter adsorpsiyonu. 2010, Ankara Üniversitesi.

34. Alkan, S., et al., Polifenol Oksidaz Enziminin Aktif Karbonla Adsorpsiyonunun izoterm ve Kinetik Analizi. Dicle Üniversitesi Fen Bilimleri Enstitüsü Dergisi, 2014. 3(1): p. 6978.

35. Kul, A.R., i. Alacabey, and N. Çalışkan Kılıç, Removal of Cobalt lons from Aqueous Solution by Diatomite. Hacettepe Journal of Biology and Chemistry, 2010. 38(2): p. 85-93. 